\title{
Scenarios for selected maritime economic functions
}

\author{
H. A. Wolters • J. Gille • J. M. de Vet • R. J. Molemaker
}

Received: 14 February 2013 / Accepted: 24 April 2013 / Published online: 13 July 2013

(C) The Author(s) 2013. This article is published with open access at Springerlink.com

\begin{abstract}
This paper discusses the use of scenarios in the 'Blue Growth' project, which was aimed at elaborating the maritime dimension of the Europe 2020 strategy, with a 15year time horizon (2025/2030). Scenarios were understood and developed in two ways: as descriptions of plausible, desirable and realistic future developments (the 'micro-future scenarios') and as a means to foster uncertainty awareness (the 'general scenarios'). The general scenarios were developed as a scenario matrix, following Van der Heijden (1996). The micro-futures were developed following the approach proposed by Miller (Futures 39:341-362, 2007). The direct impact of the general scenarios on policy development cannot yet be evaluated. The micro-futures, being relatively concrete, were very useful to trigger discussions. In addition, the evaluation of the micro-futures in the light of the general scenarios led to some valuable insights. Within the Blue Growth project, the use of this hybrid approach has led to an active involvement of stakeholders, generating energy in the process of defining a desirable future, while taking account of uncertainties in the developments in global development.
\end{abstract}

Keywords Forward looking activities $\cdot$ Scenarios $\cdot$ Maritime economic functions $\cdot$ Europe

\footnotetext{
H. A. Wolters $(\bowtie)$

Deltares, P.O. Box 85467, 3508 AL Utrecht, The Netherlands

e-mail: henk.wolters@deltares.nl

J. Gille

Ecorys, Rotterdam, The Netherlands

J. M. de Vet $\cdot$ R. J. Molemaker

Ecorys, Brussels, Belgium
}

\section{Introduction}

This paper is a case study of the application of forward looking activities in the 'Blue Growth' project. The Blue Growth project was commissioned by EC's Directorate General for Fisheries and Maritime Affairs (DG Mare). The DG Mare is the commission department responsible for the implementation of the Integrated Maritime Policy and the Common Fisheries Policy. It works to develop the potential of the European maritime economy and to secure a safe and stable supply of seafood, sustainable fisheries, healthy seas and prosperous coastal communities. ${ }^{1}$ The Blue Growth project was executed by a consortium of Ecorys (economic research and consultancy, based in Rotterdam, the Netherlands), Deltares (a water management research institute, based in Delft, the Netherlands) and Océanic Développement (a consultant on fisheries, based in Brest, France). The project ran from December 2010 to August 2012.

Scope and goals of the Blue Growth project

The project's aim was to elaborate the maritime dimension of the Europe 2020 strategy, Europe's growth strategy for the coming decade [1]. Blue Growth is hence defined as 'smart, sustainable and inclusive economic and employment growth from the oceans, seas and coasts'. The main body of work of the project consisted of the collection of evidence for the potential for such growth by analysis of statistical data, available literature and insights from experts and stakeholders. This effort covered all of Europe's sea basins (including the Outermost Regions) and a selected number of economic functions (explained in the next paragraph). The

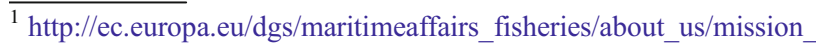
statement/index_en.htm
} 


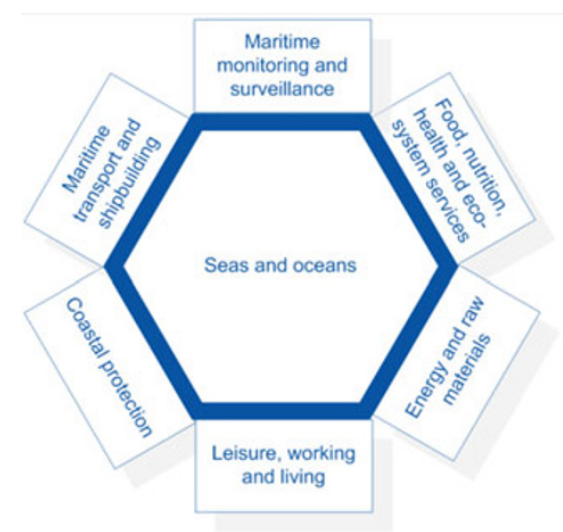

Fig. 1 The six main categories of economic uses of the seas and oceans, as identified in the Blue Growth project

resulting reports and insights provide policy-makers at EU and sea-basin level with a comprehensive, robust and consistent analysis of the present status and with focus points for policy options to support smart, sustainable and inclusive growth from the oceans, seas and coasts. The time horizon of the study was some 15 years, looking at the years $2025 / 2030$.

Maritime economic functions

The maritime economy consists of all the sectoral and crosssectoral economic activities related to the oceans, seas and coasts. While these activities are often geographically specific, this definition also includes the closest direct and indirect supporting activities (which may be land based), necessary for the functioning of the maritime economic sectors.

The list of sectors relevant in the maritime perspective is extensive. To establish a comprehensive view on economic activities that are related to sea or sea resources, the consortium has proposed to use an approach which is more closely linked to these resources, by addressing the main maritime functions of the oceans, seas and coasts. Maritime functions are defined as broad groups of economic activities that are related to the seas or to sea resources. Maritime functions thus cover the possible uses of seas and oceans by mankind. As a starting point, six main categories of functions were identified (Fig. 1).

Within these six main categories, the consortium identified a total of 27 functions, later condensed to 25 functions (Table 1). Due to time and financial constraints, the study has focused on a selection of 12 of these 25 functions, indicated in bold in Table 1 . These 12 functions were selected by three criteria: size, recent growth and future growth potential. All 25 functions were ranked according to these three criteria, and for each criterion separately, the top 7 was identified. Accounting for multiple occurrence of the same function in the three top 7's, this procedure resulted in the 12 functions mentioned. For more details of the selection procedure and criteria used, see Ecorys et al. [2].

Life cycle of the economic functions

A concept that has proven to be useful in the project was the application of the product life cycle to the economic functions, as illustrated in Fig. 2. The theory on the development stages comes from the marketing domain related to product life cycles [3]. Every product that is brought to market passes four development phases. These phases are: introduction, growth, maturity and decline. Others use different names for the same phases, or sometimes phases are split in two. The theory on market phases can be extended with the stages of product development before introduction: (pre-)development. While other researchers structure this cycle in phases with different names, the principle is similar. The concept of the life cycle

Table 1 The six main categories of maritime economic uses and the 25 economic functions as identified in the Blue Growth project

\begin{tabular}{|c|c|c|c|c|c|}
\hline $\begin{array}{l}\text { Maritime monitoring } \\
\text { and surveillance }\end{array}$ & $\begin{array}{l}\text { Food, nutrition, health and } \\
\text { ecosystem services }\end{array}$ & $\begin{array}{l}\text { Energy and raw } \\
\text { materials }\end{array}$ & $\begin{array}{l}\text { Leisure, working } \\
\text { and living }\end{array}$ & Coastal protection & $\begin{array}{l}\text { Maritime transport and } \\
\text { shipbuilding }\end{array}$ \\
\hline $\begin{array}{l}\text { Environmental } \\
\text { monitoring }\end{array}$ & Blue biotechnology & $\begin{array}{l}\text { Offshore oil and } \\
\text { gas }\end{array}$ & Coastal tourism & $\begin{array}{l}\text { Protection against } \\
\text { flooding and erosion }\end{array}$ & Short sea shipping \\
\hline \multirow[t]{4}{*}{ Maritime security } & Marine aquatic products & Offshore wind & Cruise tourism & $\begin{array}{l}\text { Preventing salt water } \\
\text { intrusion }\end{array}$ & Deep sea shipping \\
\hline & $\begin{array}{l}\text { Catching fish for human } \\
\text { consumption }\end{array}$ & $\begin{array}{l}\text { Ocean } \\
\text { renewable } \\
\text { energy }\end{array}$ & Working & Protection of habitats & $\begin{array}{l}\text { Passenger ferry } \\
\text { services }\end{array}$ \\
\hline & $\begin{array}{l}\text { Catching fish for animal } \\
\text { feeding }\end{array}$ & $\begin{array}{l}\text { Marine mineral } \\
\text { mining }\end{array}$ & Living & & $\begin{array}{l}\text { Inland waterway } \\
\text { transport }\end{array}$ \\
\hline & Agriculture on saline soils & $\begin{array}{l}\text { Carbon capture } \\
\text { and storage } \\
\text { Aggregate } \\
\text { mining } \\
\text { Desalination }\end{array}$ & & & \\
\hline
\end{tabular}

The 12 functions in bold were worked out in more detail in the study 
Fig. 2 Development stages in the product life cycle, as applied in the Blue Growth project to maritime economic functions

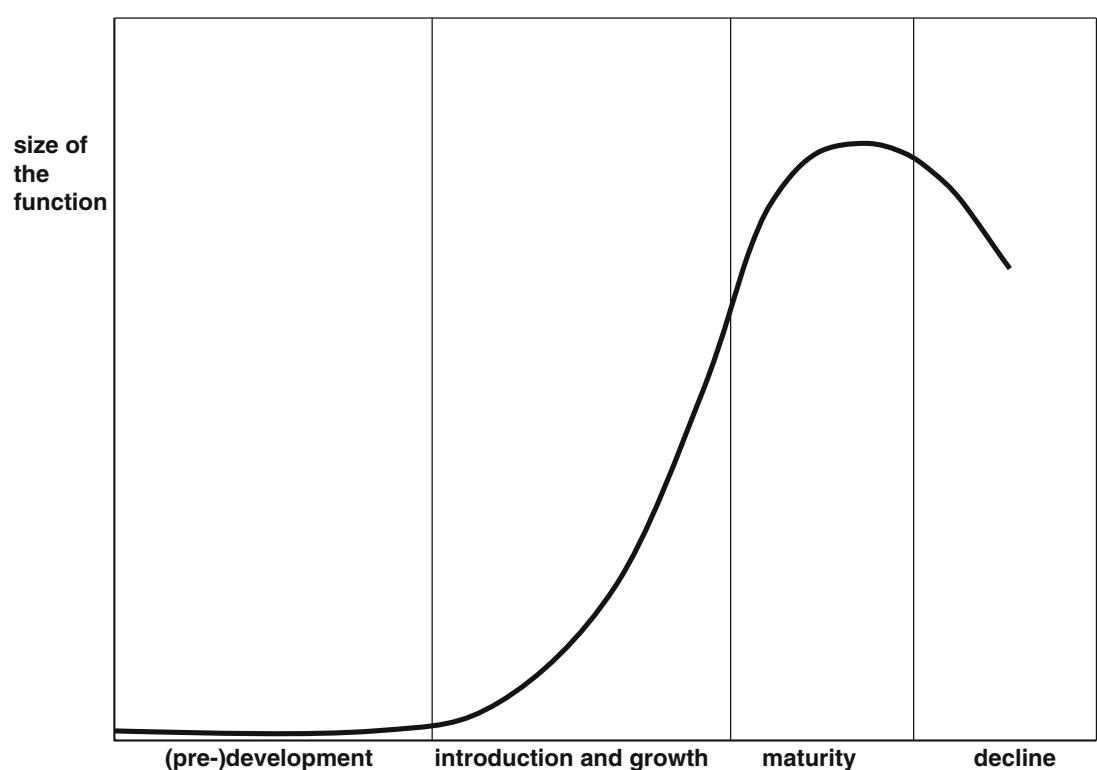

offers an easy-to-grasp explanation for certain differences found between groups of economic functions, for example, differences in business models, access to finance and critical mass.

The Blue Growth project focused on the future potential of the economic functions. Therefore, no attention was given to functions in the declining phase; no future growth potential is expected from these. This leaves the categories (pre-)development, introduction and growth and maturity.

\section{Contextual and transactional environment}

A last useful notion to be highlighted here is the distinction in literature [4] of the transactional and contextual domains in the environment of an organisation. An organisation is interpreted here in a broad sense as the group of interconnected organisations (enterprises, researchers, consultants, etc.) that together represent an economic maritime function. The contextual environment is the part of the environment that indirectly influences the organisation, but that cannot be influenced by it. The transactional environment can be influenced, to varying degrees, by the organisation, while it has a direct influence on the organisation. While this distinction helps to come to grips with the more clear-cut examples, the exact demarcation line between both types of the environment is often hard to define.

\section{A hybrid scenario approach}

\section{Use of scenarios}

An important task in the Blue Growth study was the development of scenarios for potential future developments.
During the initial stages of the project, it gradually became clear that scenarios were understood in two different ways: first as a description of the plausible, desirable and realistic future developments, aimed at the identification of initiatives that may benefit from support by DG Mare, and second as a means to develop awareness of uncertainty in future developments in order to help DG Mare develop robust policy options. These different interpretations of the term scenarios are likely to produce very different end results. These differences in interpretations are also reflected in literature, e.g. Miller [5] who discerns conceivable, possible, probable and desirable scenarios, while stressing the importance of keeping the differences well in mind. Similarly, Van der Heijden [6] separates the possible futures (described in scenarios) from probable and desired ones (described in business ideas). Because the method proposed by Miller fits well the requirements for the first interpretation of scenarios, and the one by Van der Heijden for the second, their approaches were chosen in the project.

Conceivable but impossible scenarios were not taken into consideration. The challenge in the project now was to incorporate elements of the three remaining scenario types (possible, probable and desirable ones) without mixing them up. To this end, a hybrid approach was followed which was largely similar to the one proposed in [5]. Two different types of scenarios: the 'general scenarios' and the 'micro-futures' were introduced. These two types correspond well to the contextual and transactional scenarios as identified by Van Notten et al. [7].

An additional reason to develop two scenario types stems from the issue of the geographical scale of this study. As it covers the whole of Europe, there are important differences per region and per function in what is relevant and uncertain. Building two types of scenarios, even though inspired by the 
different types rather than different scales, helps to bridge the gap.

\section{General scenarios}

The main purpose of developing the general scenarios is to identify trends and raise awareness of these trends and related threats and opportunities that have an impact on the maritime functions in the EU, in as far as they are sensitive to EU policies.

During the development and use of the general scenarios, the leading questions were: 'what is relevant' and 'what is uncertain'. The relevance of trends is reflected in the degree to which an organisation, or in this case, an economic maritime function, is sensitive to differences in the way the trend evolves. By scoring the degree of uncertainty of relevant trends, the most uncertain and relevant trends are identified, which then make up the key differences between the scenarios. The general scenario approach starts from the contextual environment (Fig. 3). In the case of policy development, literature points to the fact that the distinction between the contextual and transactional environment is often difficult to define, given the ambition of national and international policy to have wide-reaching impacts. This was also found in the discussions held during the project.

The general scenarios provide the background for the SWOT analysis of the development of the maritime economic functions, as described in the 'Micro-future scenarios' section.

\section{Micro-future scenarios}

A 'micro-future scenario', a term coined during the course of the project, is a future outlook for a particular maritime economic function. It indicates the potential of the function. Whether or not it is achieved will depend on whether the right conditions are met in terms of contextual drivers, response capacity and framework conditions. Therefore, micro-futures are not forecasts.

In the project, the micro-future scenarios were used to identify potential options for policy measures that can help to promote the smart, sustainable and inclusive development of the economic function considered (Fig. 4).

The micro-futures include a normative element, because they are designed to represent a desirable and ambitious future for the economic activity. As such, they may serve as a starting point for backcasting in a sharing and negotiation process with stakeholders, addressing questions such as 'What can or should the stakeholders do, and when, to make this future a reality'.

The desirability of these scenarios for the EC is judged by the Europe 2020 policy goals: smart, sustainable and inclusive growth [1]. Stakeholders may however apply different criteria. The balance between ambition and reality is pursued by aiming at above-average estimates, while making sure to stay rooted in the best available information from literature and interviews.

\section{Construction of the general scenarios}

The general scenarios were developed by the scenario matrix approach as explained in Van der Heijden [6]. This scenario approach provides a way to incorporate external uncertainties in the strategic planning of organisations. It starts from the possible developments in the contextual environment. Within a framework that is constructed from selected trends (the ones which are both most relevant to the organisation and most uncertain), plausible storylines are developed for the different combinations of these selected trends. The storylines are combined in scenarios, which are then used as a testing ground for planned activities.
Fig. 3 Types of environments of an organisation (after Nekkers [8])

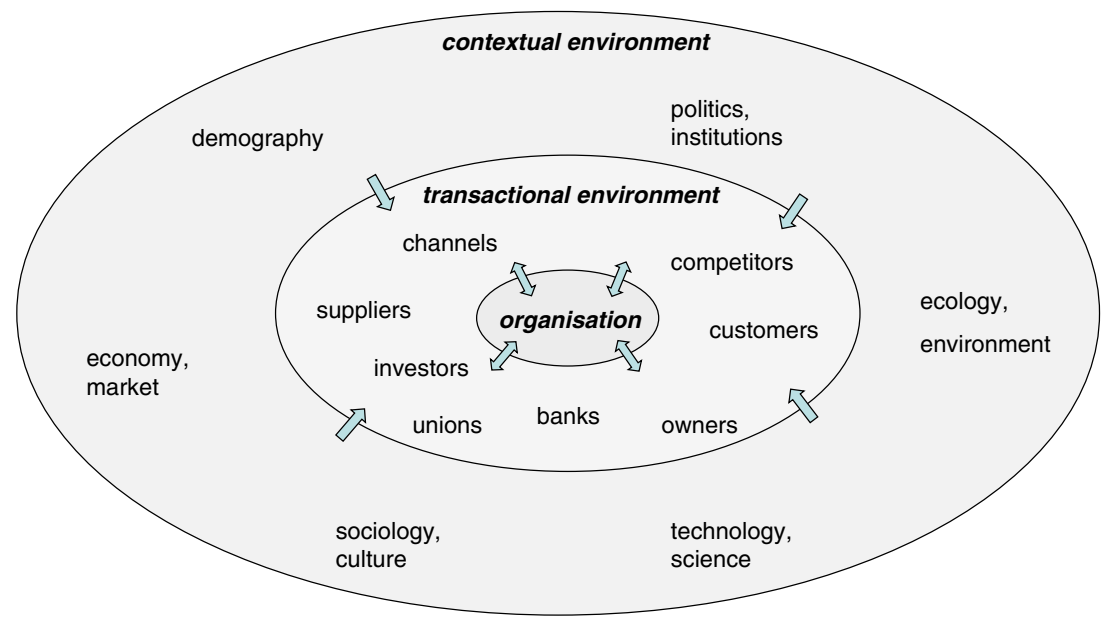




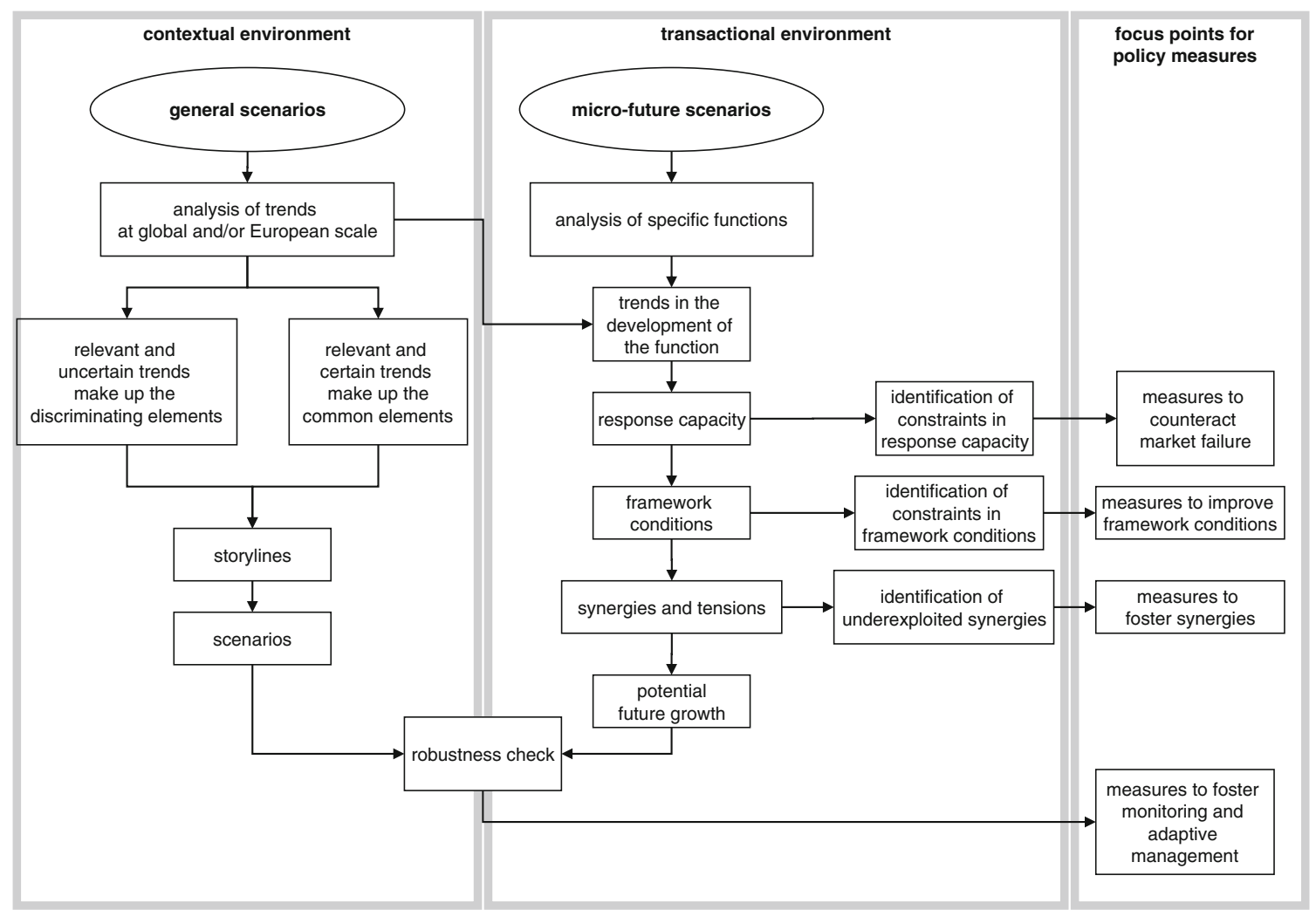

Fig. 4 Flow chart depicting the interrelations between the general scenarios, the micro-future scenarios and the focus points for policy measures

Drivers and trends in the contextual environment

The drivers in the contextual environment are organised in six main categories (Fig. 3): demography, economy and market, technology and science, environment including climate change, sociology and culture and politics and institutions. Because in this study no relevant trends in sociology and culture were identified, it has been omitted. Within the five remaining categories, important subcategories were identified in literature [9-18] as listed in Fig. 5.

Relevance and certainty of the drivers and trends

Figure 5 depicts the scores of the drivers in the contextual environment on relevance and certainty.

The indicator of relevance is the number of economic functions for which the driver was mentioned as being relevant in the detailed descriptions of the economic activities [2].

The degree of certainty was derived from the literature, cited where possible and where not available, estimated by the authors of the report. It was scored on a five-point scale (uncertain/moderately uncertain/neutral/moderately certain/ certain). Considerations in this step include the following:

- Demographic trends (population growth, increasing urbanisation, ageing population, increasing water and food scarcity, international migrations): There is broad consensus in the literature cited [15-17] on the general direction and pace of these trends. Increasing water scarcity is here understood as the scarcity that is caused by increasing demand for water by a growing population and increasing per capita use, excluding stress caused by decreasing supply, which makes up part of the environment and climate change trend mentioned below.

- Economic and market trends (economic climate, globalisation, increasing economic role of Asia, increasing price volatility, increasing scarcity of raw materials and energy, striving after self-reliance) are more controversial. In the long term, growth may be expected and the financial crisis will be overcome, but for the time horizon of 2025, developments are uncertain, especially in Europe [10]. Globalisation and striving for self-reliance are both quite persistent trends in themselves and are therefore rated as moderately certain $[10,17]$. The uncertainty arises where these two trends meet, counteracting each other. The increasing economic role of Asia is regarded as certain, at least for the coming decade; related to that, also increasing scarcity of fossil fuels and raw materials are regarded certain. Price volatility will depend on the way global governance will be shaped. This can develop in very different ways, also in the short term, and is therefore rated as moderately uncertain. 


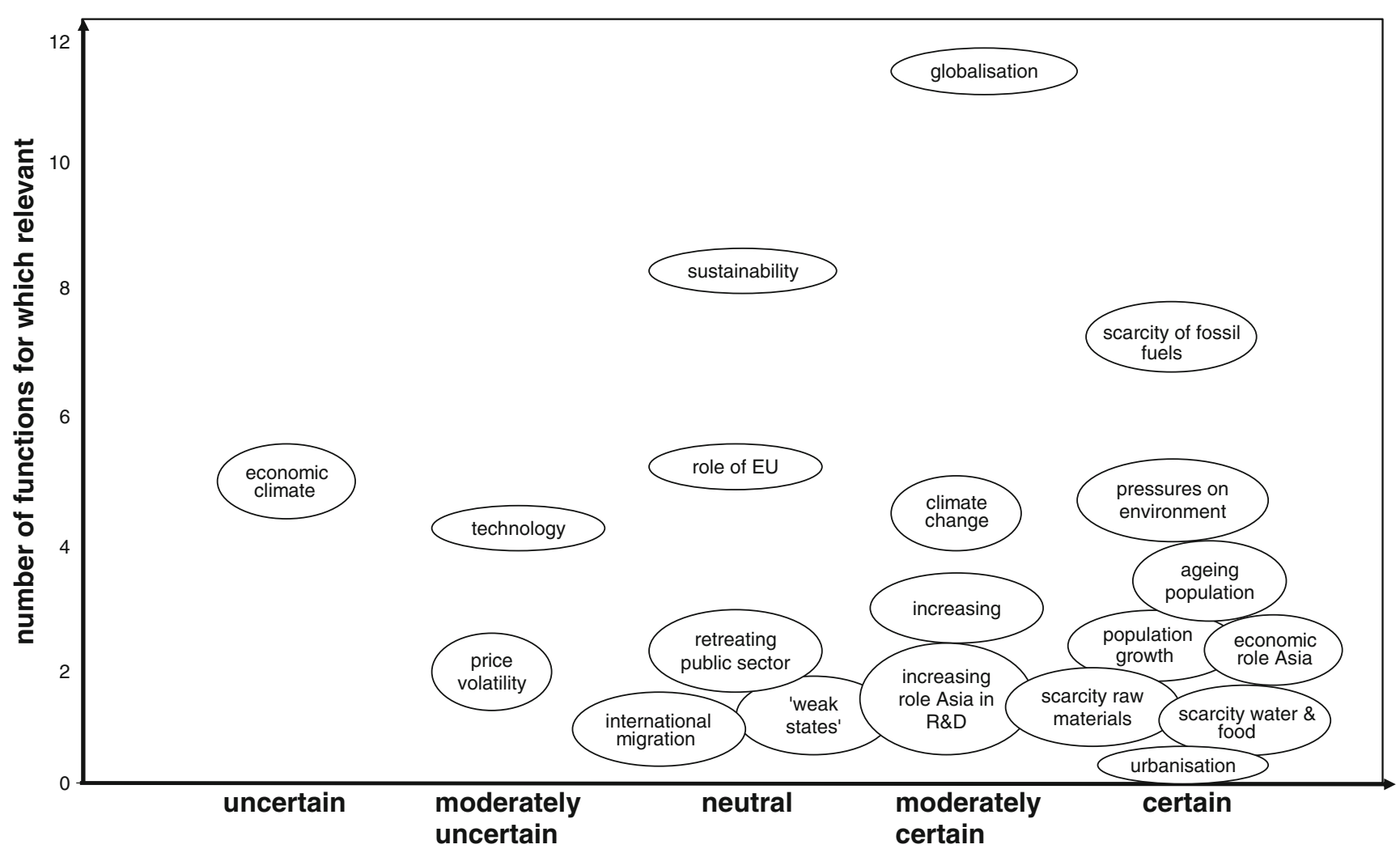

Fig. 5 Scores of 20 trends on relative certainty and relevance for 12 maritime economic functions

- Technology and science (technology as a driver for growth, increasing role of Asia): Technological development is important for virtually all maritime economic activities. In most cases, technological development is driven by the sector itself as part of its response capacity (for an explanation, see 'Construction of the micro-future scenarios') and not part of the contextual environment. Here, the scope is restricted to worldwide technological developments that offer new growth potential, such as ICT, nanotechnology and DNA technology. Also, in this respect, the upcoming role of Asia seems clear (see amongst others the R\&D mining results in [2]), therefore moderately certain. New technologies on the contrary will still have to prove their (economic) viability for the economic activities; therefore, it is rated moderately uncertain.

- Environment and climate change: Pressures on the environment and on the available space are consequences of economic and demographic trends. As these are growing, so are the expectations for the resulting environmental pressures [11]. A possible way to reverse the trend would be a transition to sustainable practices worldwide [15], and though this is a desired future state, it is not expected to be reached within the time horizon of this study. Climate change and sea level rise are expected to continue.

- Politics and institutions (increasing role of EU, increasing emphasis on sustainability, retreating public sector, development of (weak states') are overall the most uncertain category of drivers. The role of the EU is that of a driver in the contextual environment for nongovernmental stakeholders, while for DG Mare, it is part of both the contextual and the transactional environment. On balance, the bias is on the contextual character of this driver. By its nature, it implicitly includes normative uncertainties, i.e. uncertainty in the ways the general public looks at the tasks and roles of authorities at local, national and EU level.

Figure 5 shows that globalisation is the most frequently mentioned trend. Globalisation and increasing international competition are relevant to all economic activities investigated. They thereby provide a strong urge to look beyond the EU borders. In most, but not all economic activities, these drivers are seen as a threat.

Political and regulatory commitments to sustainability are mentioned eight times (out of 12). For some economic activities, this driver is seen as a constraint or a source of an unequal playing field (e.g. in short sea shipping, because European regulation is stricter than average). For others, it is an important incentive to growth because it directly (as in environmental monitoring) or indirectly (as in offshore wind energy and ocean energy) favours the function.

Increasing scarcity of fossil fuels is a recognised $[10,14]$ and here re-confirmed driver for the majority of the economic activities considered. As with sustainability, some 
economic activities are favoured by this trend (offshore wind, ocean renewable energy), while others are affected adversely (coastal tourism, cruise tourism). The effect of the driver on the economic function 'offshore oil and gas' is ambiguous. Increasing scarcity signals the end of activities, but increasing prices are incentives to new explorations.

Construction of the scenario matrix

The top 5 for combined scores on relevance and uncertainty are: economic climate, technology, increasing price volatility, growing emphasis on sustainability and the increasing role of the EU. These trends provide the differentiating factors between scenarios.

The top 5 for combined scores on relevance and certainty are: globalisation, increasing scarcity of fossil fuels, increasing pressures on the environment, ageing population and the increasing role of Asia. These trends are included in all of the scenarios.

From the five most relevant and uncertain drivers, economic climate and increasing price volatility were combined, coupling for both drivers the worst and best situations. Technology is included in the storylines of the scenarios, as it often correlates well with economic development. The increasing role of the EU was not taken into consideration here, in order not to repeat discussions which are already sufficiently addressed. The resulting axes of the scenario matrix are: slowly recovering, strongly fluctuating world economy vs. stable worldwide economic development and limited vs. strong emphasis on sustainability.

The resulting four scenarios are outside the direct control of policies - and representing possible futures. The scenarios can have a significant impact on the way in which Europe's Blue Growth develops, as the potential for Blue Growth maritime economic activities will vary depending on the scenario that will materialise (Fig. 6).

In Table 2, the four general scenarios are described in more detail for the aspects economy, science and technology, environment and climate, international relations and the role of public authorities.

\section{Construction of the micro-future scenarios}

Micro-future scenarios were developed roughly following step 1 of Riel Miller's Hybrid Strategic Scenario method [5]. In this step, awareness is developed and shared and implicit knowledge (about expectations, values, expected

\section{Fragile recovery}

- low average growth

- many 'boom and bust' cycles

- low predictability

- focus on mid to short term

- conviction of the need for sustainability

- learning to capitalise on the 'boom' phases, attenuating the effects of 'bust' phases

\section{strong emphasis on sustainability}

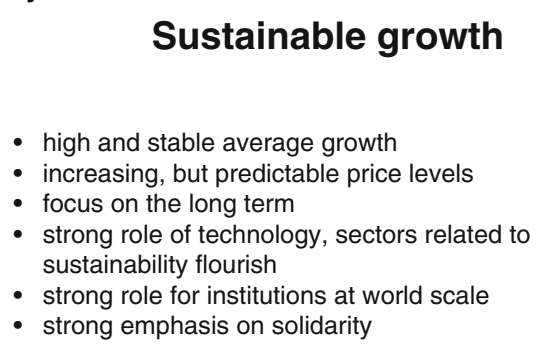

\section{Sustainable growth}

- high and stable average growth

- increasing, but predictable price levels

- focus on the long term

- strong role of technology, sectors related to sustainability flourish

- strong role for institutions at world scale

- strong emphasis on solidarity

slowly recovering, strongly fluctuating world economy Boom and bust

- low average growth

- many 'boom and bust' cycles

- during 'bust' mass unemployment, social unrest

- focus on short term

- little stimulus for long-term innovation

- 'take care of yourself' attitude prevails

Fig. 6 Scenario matrix for Blue Growth's general scenarios 


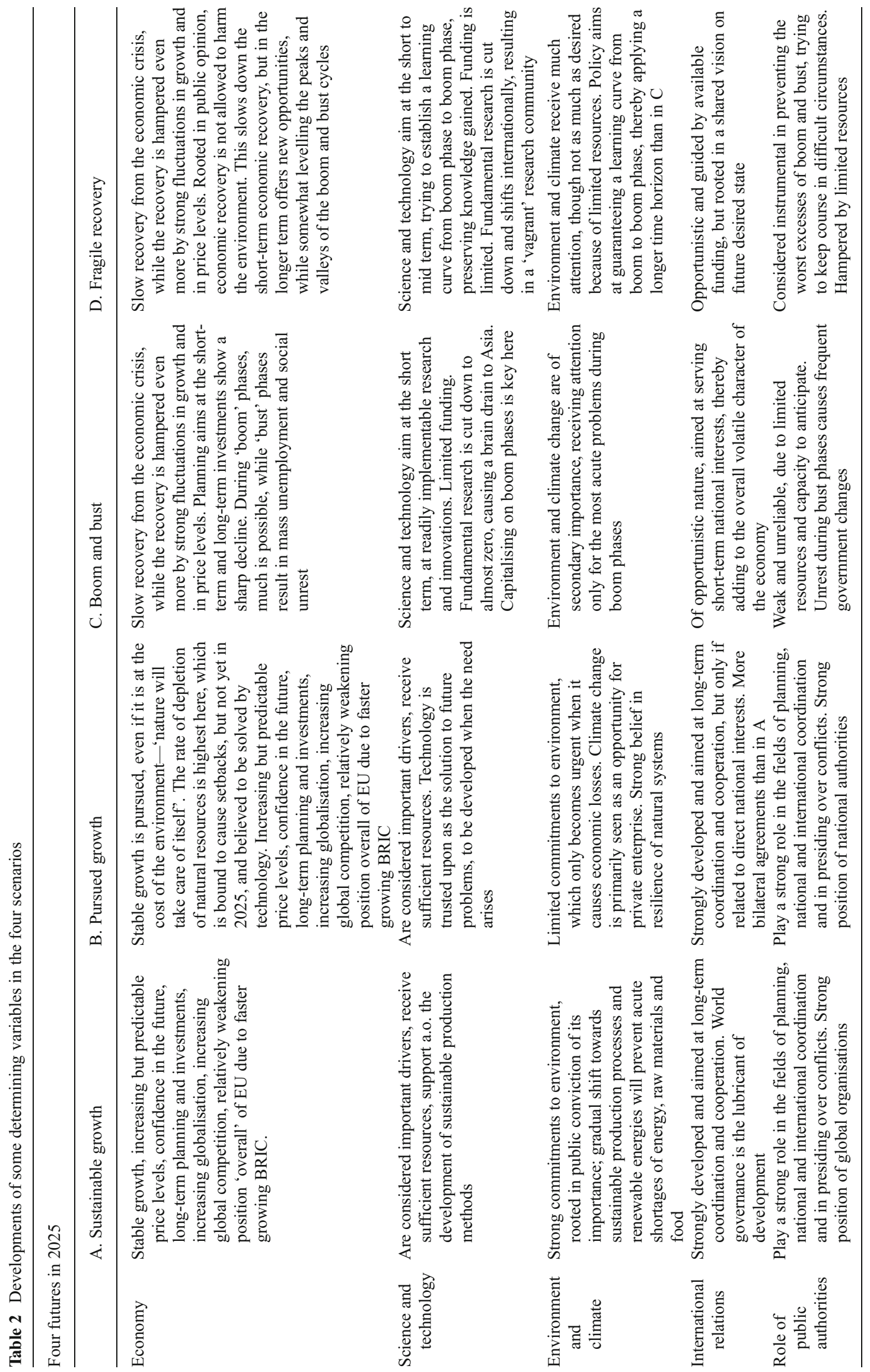


developments over time) is made explicit. The analytical framework for this step was developed in the study [2] and comprises the following building blocks:

Drivers in the contextual environment: a selection of the drivers described in the previous section, relevant for the function.

Response capacity: The capacity and capability of a function to respond to drivers in the contextual environment and to global market conditions. Similar terms are resilience or adaptive capacity. The response capacity is determined by a variety of elements, which include:

- Adjustment capacity to new regulations, including those in the area of environment, energy and emissions

- Structure and organisation, covering the overall structure of the function in terms of, for example, enterprise composition (size), specialisation and segmentation, economies of scale and scope, geographical clustering, company formation, growth and closure, etc.

- Firm strategies and business models, covering the different strategies followed by companies and organisations (e.g. cost-based, innovation-driven, branding and marketing)

- Production process, including the economies of scale and existing (in-)efficiencies in the function

- Industrial innovation and technological development, covering the management and organisation of production processes within the sector including, for example, not only technology utilisation, but also product and service development

- Value chain relationships, covering the upstream (backward) and downstream (forward) linkages between industry (and other) sectors and markets

It is through the interplay between these elements that the resilience of EU maritime functions is determined, and that market performance is attained - with profitability, productivity and employment as important outcomes.

Framework conditions cover a broad range of determinants shaping the business environment. They may be influenced directly or indirectly by policy measures. Essentially, this covers aspects of the business and operational environment that are external to individual (and collective) business operations of firms within the sector, but internal to policy makers at national and EU level, such as legal and regulatory frameworks, infrastructure, knowledge, labour force and skills, access to finance and public acceptance. Also, geographical characteristics are included here which are not influenced by policy.

The use of the development stages (Fig. 2) was particularly helpful in grouping the similarities and differences in the response capacity and the framework conditions of the functions [2].
Synergies and tensions: environmental impacts of each of the economic functions; synergies and tensions between economic functions.

Potential development: If the drivers in the contextual environment and the function responses evolve as sketched, the outcome or 'impact' of the function can be estimated in terms of economic (GDP and employment) and environmental indicators (e.g. water quality, air quality, waste production). This is called the potential development of the function.

As an example, a summary of the micro-future scenario for the function 'marine mineral mining', a function in the (pre-)development stage, is included in the text box below.

Micro-future scenarios like the one summarized here were developed for 12 out of the 25 economic functions, the ones indicated in bold in Table 1. The reports can be downloaded from the DG Mare website. ${ }^{2}$ The reports were composed by a core expert team, based on available literature, completed and improved with the results of some 120 interviews and with inputs obtained during a 2-day expert meeting.

Marine mineral mining: a micro-future scenario

Marine mineral mining is still in an infant state. No excavation of solid minerals has taken place beyond $200 \mathrm{~m}$ below sea surface. Although the notion that the seabed might contain large mineral deposits exists for decades, the exploration was yet too costly. The technology for deep sea mining was not mature enough and the market price of these raw materials was not at a level that could support costly deep sea exploration. In the past few years, this is changing, as the market prices of most of these minerals have gone up significantly due to a combination of increased demand and increased supply risk. The increased demand is also driven by technological developments. Many of these minerals are important raw materials in high-tech applications. With the rise of the computer and mobile communication era, the demand for rare earths has steepened, and shortages are imminent - for geopolitical rather than for geological reasons.

Meanwhile, land mines can no longer meet the growing demand.

In ocean floors around the globe, vast stocks of minerals are expected to be found. Based on interviews and literature, in [2], the estimates are that by $2020,5 \%$ of the world's precious minerals including cobalt, copper, zinc as well as rare earths can come from the ocean floors and by 2030 up to $10 \%$. A surge in marine mineral mining is expected to start after 2013, should the first commercial venture for polymetallic sulphides ('Solwara 1') succeed. Commercial excavation of copper and gold from the Exclusive Economic Zones of Papua New Guinea is expected to start in 2013 by the Canadian Nautilus mining company. Processing and smelting of the copper will take place in China. The Nautilus mining company has ordered a dedicated ship from a German shipyard. It will also use state-of-the art extraction tools, such as remotely operated vehicles (ROVs), cutters and risers developed for deep sea oil winning - supplied by European partners. The exploration of the largest known sulphide concentration, namely in the Red Sea, will soon start as well.

\footnotetext{
${ }^{2}$ https://webgate.ec.europa.eu/maritimeforum/content/2946
} 
The extent to which European actors can benefit from this activity (an important matter in the light of the Europe 2020 Strategy) will depend on the strategy of major mining companies (many of which are from the USA, Australia and Canada) and their ability to obtain licenses. European companies are amongst the world leaders in key technologies such as dredging, drilling, cutting, transport and ROVs.

Uncertainties that surround this activity are market prices for minerals that need to remain consistently high on world markets. The metal contents found in deposits on the ocean floor need to be high.

Technologies still need to be tested, mostly in the area of excavation devices, cutters and risers - through Nautilus' Solwara project at the Papua New Guinea coast. Cost reductions need to be achieved, particularly with regard to transport costs. Furthermore, the future of deep sea mining is expected to depend on overall public acceptance, as well as that of local communities.

Marine mineral mining can bring about considerable but yet unknown environmental concerns, through the disturbance of deep sea ecosystems. This is considered a major tension related to this activity. The deep sea and sea floor form an extensive and complex system which is linked to the rest of the planet in exchanges of matter, energy and biodiversity. Operations on the sea floor may destroy unique habitats and disturb deep sea ecosystems which could entail changes in fish stock and primary production. Pressures and impacts may also emerge from future activities related to mining, as well as carbon sequestration and gas hydrate extraction. These activities may result in loss of biodiversity and reduce the flow of ecosystem services.

Synergies may develop between marine mineral mining and oil and gas exploration and offshore industry, also through strengthening demand for dedicated ships. Marine mineral mining also provides synergies with blue biotechnology, notably by offering the infrastructure and support for exploration into new and rare species.

The most prominent framework conditions that need to be fulfilled to achieve the potential growth are as follows:

- Access to private capital for investment and upscaling

- Environmental impacts remain under control

- Acceptance of local coastal populations exposed to mining activities

- International legal framework: conditions for licensing in international waters

\section{The maritime economic functions in the four general scenarios}

The micro-futures were reviewed in the light of the principal uncertainties of the general scenarios. The overarching question is how these maritime economic activities are likely to unfold in the different general scenarios and to review whether the conditions for utilising the future potential are likely to be met.

Blue Growth prospects appear to profit most from a sustainable growth scenario-as stable economic growth combined with a growing environmental awareness and actions provide an excellent context for the majority of economic functions analysed. The long-term orientation of actors in this scenario contributes to a stable investment climate, particularly favourable for blue biotechnology, offshore wind and ocean renewable energy. Added to this scenario can be a flourishing deep sea and short sea shipping (replacing substantial parts of road transport), enhanced port facilities and capacities, a strongly increasing (sustainable) tourism sector and high investment levels in technologies for exploitation of marine biodiversity. An increasing role of the seas and oceans in human food production (sustainable aquaculture), intensified monitoring activities and intensified international coordination of the use of marine space also fit well in this scenario. In this scenario, expectations are particularly high for offshore wind, ocean renewable energy, blue biotechnology and marine aquatic products. Within several of these domains, Europe is in a leading position when it comes to technology and innovation: it has generated around half of the reviewed patents in offshore wind and some $25 \%$ of the reviewed patents in ocean renewable energy sources. A strong performance can also be recorded in sustainable innovations for marine aquatic products. Furthermore, Europe is well placed to lead not only in the transformation of traditional maritime economic activities, e.g. green shipping, sustainable tourism, sustainable aquaculture, but also promoting more sustainable forms of business within oil and gas or marine mineral mining. Playing out the card of sustainable maritime innovations is likely to produce growth and jobs in a world which is increasingly aware of sustainability. This card is however less likely to be played successfully in a world which is short-term oriented and where Europe moves from crisis to crisis.

A pursued growth scenario will also provide opportunities, especially for the mature and growing activities. In this scenario, one may expect a flourishing deep sea and short sea shipping, enhanced port facilities and capacities, increasing coastal tourism in northern Europe driven by climate change effects and an increased demand for short trips, a strong cruise shipping sector. Also, high investment levels in technology, an increased role of the seas and oceans in traditional human food production and a persisting extraction of oil, gas and minerals from the deep seas (including the Arctic), supplemented by extensive monitoring activities, fit well in this scenario. Environmental awareness will however be lower.

Prospects will be more selective and limited in the fragile recovery scenario, which combines a low and unstable economic performance with a strong development of environmental awareness. Fluctuating transport volumes result in obsolete fleets and port facilities, a stable or declining cruise shipping sector and limited investments in developing technologies aimed at sustainability. Extraction of oil and gas is slowly declining and taken over by renewables, while the extraction of minerals from deep seas is slow to develop.

Within the boom and bust scenario, prospects are expected to be considerably less favourable-due above all to a short-term horizon of all actors, more risk-averseness, a low level of environmental awareness and restricted public and private investment budgets. Fluctuating transport 
volumes result in obsolete fleets and port facilities. Extraction of oil and gas from the deep seas continues, though without the necessary investments, because commodity price fluctuations add to uncertainty. Coastal tourism and cruise tourism will be relatively stable, with a focus on northern Europe due to climate change effects. Only limited investments are expected in developing new technologies, with dimmed prospects for offshore wind, ocean renewable energy and blue biotechnology as a consequence. Public resources for maritime monitoring activities will be limited. Especially in this scenario, additional policy support is likely to be needed.

\section{Discussion and concluding remarks}

In the course of the Blue Growth project, no opportunity could be found to perform a dedicated evaluation of the impact of the scenario work (apart from the evaluation of the project as a whole, which was performed following regular EC procedures). The notes in this section are therefore based on the observations of the authors only.

Literature (e.g. $[6,7])$ shows that the impacts of scenarios may be divided in impacts on process and on content. Smith [19] presents a comprehensive tool for impact measurement of foresight studies, partly based on work done by Calof and Smith [20] and Johnston [21]. Smith introduces seven categories with a total of 54 measures to assess the impact of foresight studies. This structured approach was used by the authors as a checklist for a qualitative identification of the most relevant impacts (without repeating the full list of 54 measures):

- The primary client affected is DG Mare; for this client, the key roles of the scenarios were awareness raising and providing information.

- The primary benefits of the foresight study are related to the support that it provides to the development of a strategy to achieve the EU2020 goals;

- Secondary benefits may be expected in the future through the establishment of new interconnections between stakeholders, which is important because of the high potential of synergies between economic functions that the study has identified.

- The study has identified and partially involved the main stakeholders (during the stakeholder day and the expert meeting), thus adding to future policy support.

- The study has framed the main policy issues and options, even though these have to be studied in more detail before they can be implemented.

- The study has identified the main threats and opportunities for these policy measures.
The micro-futures' main impact has been their central role in sketching the potential future developments in the maritime functions. By their nature, the micro-futures are based on trend analyses, more so than the general scenarios. Their concrete and quantitative nature made them useful in triggering discussions during the meetings and in electronic communication with stakeholders, thus helping in evoking reactions, discussions and inputs that have contributed to improving the storylines. The descriptions of the present framework conditions and fields of desired policy measures, as incorporated in the micro-futures, have helped strongly in drafting the schematic overview of relevant policy fields to be considered in follow-up activities.

The general scenarios were used to test the robustness of the developments in the micro-futures ('The maritime economic functions in the four general scenarios'). The general scenarios were presented during the expert meeting and the stakeholder meetings that were organised in the project. Their use during these meetings was not evaluated explicitly. The authors' tentative conclusion is that, for policy makers, the incorporation of uncertainty (as represented by the general scenarios) is more difficult than the incorporation of ambition (as represented by the micro-futures). As a consequence, the impact of the general scenarios is not as visible as that of the micro-futures.

It is too early to evaluate the impact of the scenarios on DG Mare's actual policy development, because DG Mare has not yet specified new policy measures as based on the study. Some impacts are visible; for example, some of the insights of the Blue Growth final report have been used in the EC communication on Blue Growth [22]. Furthermore, DG Mare has embarked on various follow-up activities with respect to blue growth, which can be said to prove at least that the perspectives offered in the scenarios are favourable.

Open Access This article is distributed under the terms of the Creative Commons Attribution License which permits any use, distribution, and reproduction in any medium, provided the original author(s) and the source are credited.

\section{References}

1. EC (2010) Europe 2020 - a strategy for smart, sustainable and inclusive growth. Brussels, COM(2010) 2020 final

2. Ecorys, Deltares and Océanic Développement (2012) Blue Growth final report. https://webgate.ec.europa.eu/maritimeforum/content/ 2946. Accessed 15 Jan 2013

3. Perreault WD Jr, Cannon JP, McCarthy EJ (2012) Essentials of marketing: a marketing strategy planning approach. McGraw Hill, New York

4. Emery FE, Trist EL (1965) The causal texture of organizational environments. Hum Relat 18:21-32

5. Miller R (2007) Futures literacy: a hybrid strategic scenario method. Futures 39:341-362 
6. Van der Heijden K (1996) Scenarios: the art of strategic conversation. Wiley, Chichester

7. Van Notten PWF, Rotmans J, van Asselt MBA, Rothman DS (2003) An updated scenario typology. Futures 35:423-443, http://eur-lex.europa.eu/LexUriServ/LexUriServ.do?uri=COM: 2010:2020:FIN:EN:PDF

8. Nekkers J (2006) Wijzer in de toekomst-werken met toekomstscenario's. Business Contact, Amsterdam (in Dutch)

9. EC (2011) Tackling the challenges in commodity markets and on raw materials. Brussels, COM(2011)25 final. http://eur-lex.europa.eu/ LexUriServ/LexUriServ.do?uri=COM:2011:0025:FIN:en:PDF. Accessed 10 Jan 2013

10. EC, DG Research (2009) The world in 2025; rising Asia and socioecological transition. Directorate-general for research socio-economic sciences and humanities. doi:10.2777/2539

11. EEA (2010) The European environment - state and outlook 2010: synthesis. European Environment Agency, Copenhagen. Luxembourg: Publications Office of the European Union, 2010. doi: $10.2800 / 45773$

12. IEA (2009) World energy outlook 2009. International Energy Association, Paris.

13. Lennert M, Robert J (2007) Scenarios on the territorial future of Europe. Espon project 3.2

14. Shell (2008) Shell energy scenarios to 2050. Shell International BV, The Hague. http://s00.staticshell.com/content/dam/shell/static/future- energy/downloads/shell-scenarios/shell-energy-scenarios2050.pdf. Accessed 10 Nov 2012

15. UK Government Office for Science (2011) Foresight. The future of food and farming (2011) Final project report. The Government Office for Science, London

16. UN (2007) World urbanization prospects: the 2007 revision population database. Department of Economic and Social Affairs: Population Division

17. US National Intelligence Council (NIC) (2008) Global trends 2025: a transformed world

18. IPCC (2007) Climate change 2007: synthesis report. Contribution of working groups I, II and III to the fourth assessment report of the intergovernmental panel on climate change. In: Pachauri RK, Reisinger A (eds) Core writing team. IPCC, Geneva, Switzerland, p 104

19. Smith JE (2012) Measuring foresight impacts. Foresight brief no. 249, http://www.foresight-platform.eu/brief/efp-brief-no-249-measuring-foresight-impact/. Accessed 6 April 2013

20. Calof JL, Smith JE (2010) Critical success factors for governmentled foresight. Sci Public Policy 37(1):31-40

21. Johnston R (2012) Developing the capacity to assess the impact of foresight. Foresight 14(1):56-68

22. EC (2012) Blue growth - opportunities for marine and maritime sustainable growth. EC $\operatorname{COM}(2012) 494$ final. http://ec.europa.eu/ maritimeaffairs/policy/blue_growth/documents/com_2012_494_en.pdf. Accessed 15 Jan 2013 